\title{
Lipopolysaccharide regulates MMP-9 expression through TLR4/NF-кB signaling in human arterial smooth muscle cells
}

\author{
HONGLI LI* HAO XU* and BAOGUI SUN \\ Department of Cardiology, Shanghai First People's Hospital, College of Medicine, \\ Shanghai Jiaotong University, Shanghai 200080, P.R. China
}

Received February 3, 2012; Accepted June 12, 2012

DOI: $10.3892 / \mathrm{mmr} .2012 .1010$

\begin{abstract}
Matrix metalloproteinases (MMPs) are critical to vascular smooth muscle cell migration in vivo. The dysregulation of MMPs is involved in the pathogenesis of abnormal arterial remodeling, aneurysm formation and atherosclerotic plaque instability. It has been confirmed that lipopolysaccharides (LPS) constitute a strong risk factor for the development of atherosclerosis. In this study, we aimed to determine a potential mechanism of LPS on MMP-9 expression in human arterial smooth muscle cells (HASMCs). RT-PCR analysis was used to detect MMP-9 mRNA expression and western blot analysis was performed to examine MMP-9 protein expression. An electrophoretic mobility shift assay was also employed to determine NF- $\kappa B$ binding activity. Results showed that LPS induced MMP-9 mRNA and protein expression in HASMCs in a TLR4-dependent manner. Notably, upon blocking the NF- $\mathrm{KB}$ binding with pyrrolidine dithiocarbamate, it was demonstrated that the expression of MMP-9 by LPS occurs through TLR4/NF- $\kappa B$ pathways. It was concluded that LPS induced

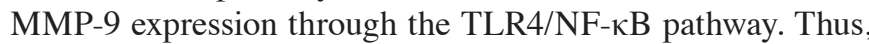
the TLR4/NF- $\mathrm{KB}$ pathway may be involved in the pathogenesis of atherosclerosis.
\end{abstract}

\section{Introduction}

The matrix metalloproteinases (MMPs) are a family of peptidase enzymes responsible for the degradation of extracellular matrix components, including collagen, gelatin, fibronectin, laminin and proteoglycan (1). Currently, more than 20 different members of the MMP family have been identified. Based on sequence homology and substrate specificity, MMPs are classified into collagenases, stromelysins, gelatinases,

Correspondence to: Dr Baogui Sun, Department of Cardiology, Shanghai First People's Hospital, College of Medicine, Shanghai Jiaotong University, 100 Haining Road, Shanghai 200080, P.R. China E-mail: baoguisun@yahoo.cn

*Contributed equally

Key words: lipopolysaccharide, toll-like receptor 4, matrix metalloproteinases, nuclear factor- $\mathrm{kB}$ membrane-type and other MMP sub-families (2). The activity of MMPs is known to be associated with cardiovascular diseases, including atherosclerosis (3), restenosis following angioplasty (4), dilated cardiomyopathy $(5,6)$ and myocardial repair following infarction (7).

MMP-9 is classified into the gelatinases sub-family. MMP-9 cleaves gelatin, collagens IV, V and XIV, aggrecan, elastin, entactin and vitronectin. Endothelial cells, smooth muscle cells, fibroblasts and infiltrating inflammatory cells are able to produce MMP-9. It is generally recognized that MMP-9 is involved in smooth muscle cell migration in vivo and in vitro (8-10). Accordingly, MMP-9 expression is markedly enhanced in vascular stenosis following experimental balloon dilation and arterial restenosis following angioplasty (11). The transcription of MMP-9 genes is differentially activated by phorbol esters, lipopolysaccharides (LPS) and staphylococcal enterotoxin B (SEB). Previous studies demonstrated that the expression of MMP-9 is upregulated in the liver, spleen and kidney following bacterial LPS administration $(12,13)$, and that selective deletion of the MMP-9 gene protects against LPS-induced mortality (13). MMP-9 expression is also induced by LPS in human aortic smooth muscle cells (HASMCs) (14). However, how LPS regulates MMP-9 expression remains to be determined. Since HASMCs express TLR4 and MMP-9, and LPS upregulates MMP-9 expression in HASMCs, we hypothesized that LPS upregulates MMP-9 expression in HASMCs through the TLR4 pathway. In the present study, we demonstrated that LPS upregulates MMP-9 expression in HASMCs through TLR4-NF- $\kappa \mathrm{B}$ signaling.

\section{Materials and methods}

Materials. HASMCs and medium 231 were obtained from Cascade Biologics (Portland, OR, USA). LPS from Escherichia coli and pyrrolidine dithiocarbamate (PDTC) were purchased from Sigma (St. Louis, MO, USA). Neutralizing anti-TLR4 (HTA125) antibodies were obtained from Santa Cruz Biotechnology, Inc. (Santa Cruz, CA, USA). The anti-human MMP-9 polyclonal antibody used in the western blot analysis was from Santa Cruz Biotechnology, Inc.

Cell culture. HASMCs were cultured in medium 231 supplemented with 5\% SMGS [5\% fetal bovine serum, recombinant human basic fibroblast growth factor, recombinant human 
epidermal growth and insulin (Cascade Biologics)]. After cells in the medium reached $80 \%$ confluence, HASMCs were dislodged from the surface of the flask using trypsin/EDTA solution, washed and resuspended in supplemented medium 231. The cells were subcultured at ratios of 1:3. Subsequent experiments were conducted using passages 5-7.

$R T-P C R$. Total RNA was extracted from resting or chemical agent-stimulated HASMCs using TRIzol ${ }^{\circledR}$ reagent according to the manufacturer's instructions (Invitrogen Life Technologies, Carlsbad, CA, USA). Total RNA (1 $\mu \mathrm{g})$ was used as a template to make the cDNA using a reverse trancription kit (BioDev Scientific \& Technical Co., Ltd., China). PCR amplification was performed with $\mathrm{Taq}$ polymerase for 32 cycles of $45 \mathrm{sec}$ at $95^{\circ} \mathrm{C}, 30 \mathrm{sec}$ at $62^{\circ} \mathrm{C}$ and $1 \mathrm{~min}$ at $72^{\circ} \mathrm{C}$ (for MMP-9 and GAPDH). The primer sets used to amplify MMP-9 were 5'-gacatcgtcatccagtttgg-3' (sense) and 5'-tggccttggaagatga atgg-3' (antisense), yielding a 398-bp fragment. The primer sets used to amplify GAPDH were 5'-cagggctgcttttaactctg-3' (sense) and 5'-gaagatggtgatgggatttc-3' (antisense), yielding a 175-bp fragment. The MMP-9 and GAPDH RT-PCR products were confirmed by electrophoresis on a $1.5 \%$ agarose gel and sequencing analysis.

Western blot analysis. HASMCs were washed with ice-cold phosphate-buffered saline (PBS), and lysed for $20 \mathrm{~min}$ on ice with lysis buffer containing $20 \mathrm{mM}$ Tris- $\mathrm{HCl}$ (pH 8.0), $137 \mathrm{mM}$ $\mathrm{NaCl}, 10 \%$ glycerol, $1 \% \mathrm{NP}-40,2$ mM EDTA, 5 mM DTT and $10 \mathrm{mM}$ PMSF. Following lysis, the lysates were centrifuged for $4 \mathrm{~min}$ at $12,000 \mathrm{rpm}$, and the supernatants were collected in fresh tubes kept on ice. Protein concentrations in each sample were determined using a bicinchoninic acid (BCA) assay. Total protein $(100 \mu \mathrm{g})$ was mixed with loading buffer with the anionic denaturing detergent sodium dodecyl sulfate (SDS), boiled at $100^{\circ} \mathrm{C}$ for $5 \mathrm{~min}$, and then resolved by $10 \%$ SDS polyacrylamide gel electrophoresis. The proteins were transferred onto a polyvinylidene fluoride membrane. After blocking the membrane in Tris-buffered saline Tween-20 (TBST) containing non-fat milk for $1 \mathrm{~h}$ at $4^{\circ} \mathrm{C}$ under agitation, the membrane was washed three times in TBST and incubated for $2 \mathrm{~h}$ with anti-human MMP-9 antibody (1:200; Santa Cruz Biotechnology, Inc.,) or GAPDH monoclonal antibody (1:200; Santa Cruz Biotechnology, Inc.,). After washing three times in TBST, membranes were incubated with HRP-conjugated mouse anti-human IgG (1:100; Santa Cruz Biotechnology, Inc.,) at room temperature for $1 \mathrm{~h}$ and then washed three times with TBST. IgG bands were detected using a streptavidin amplification reagent according to the manufacturer's instructions, and visualized using a ProtoBlot ${ }^{\circledR}$ II AP system (Promega Corporation, Madison, WI, USA).

Electrophoretic mobility shift assay. Nuclear extract was prepared according to the Nuclear Extract kit manufacturer's instructions (Active Motif, Carlsbad, CA, USA). The oligonucleotides containing the $\mathrm{NF}-\kappa \mathrm{B}$ binding site (5'-agttgaggg gactttcccaggc- $3^{\prime}$ ) were radiolabeled with $\gamma-{ }^{32} \mathrm{P}$-ATP using a T-4 polynucleotide kinase (Promega Corporation). Binding reactions were performed with $10 \mathrm{mg}$ of nuclear protein in $10 \mathrm{mM}$ Tris, $1 \mathrm{mM}$ DTT, $1 \mathrm{mM}$ EDTA, 5\% glycerol, $0.1 \%$ Triton X-100, $1 \mathrm{mg}$ poly (dIdC), $5 \mathrm{mg}$ BSA and $\gamma^{32} \mathrm{P}$-labeled oligonucleotide. Subsequently, the reaction mixture was separated on 5\% non-denaturing polyacrylamide gels for separation from the unbound oligonucleotides according to the manufacturer's instructions (Promega Corporation).

Statistical analysis. Quantitative data were presented as the mean \pm standard deviation (SD). For comparison between multiple groups, the data were analyzed by ANOVA and the Student-Newman-Keuls post-hoc analysis. $\mathrm{P}<0.05$ was considered statistically significant. SPSS 11.5 (SPSS Inc., Chicago, IL, USA) was used for statistical analysis.

\section{Results}

LPS induced MMP-9 expression in HASMCs in a TLR4dependent manner. Unstimulated HASMCs expressed low levels of MMP-9 mRNA, however, the expression was upregulated upon treatment with LPS at $10 \mathrm{ng} / \mathrm{ml}$ for $24 \mathrm{~h}$ (Fig. 1A). To confirm that the purified LPS signals through TLR4, we treated HASMCs with anti-TLR4 neutralizing antibodies or control $\mathrm{IgG}(10 \mu \mathrm{g} / \mathrm{ml})$ for $2 \mathrm{~h}$ prior to the addition of LPS. Our results demonstrate that anti-TLR4 neutralizing antibody pre-treatment reduces LPS-mediated MMP-9 mRNA expression (Fig. 1B). However, the addition of control IgG did not affect LPS-mediated MMP-9 mRNA expression. Furthermore, neutralizing anti-TLR4 did not affect on MMP-9 mRNA expression in HASMCs (Fig. 1B).

We examined the expression of MMP-9 protein in response to LPS. Untreated HASMCs exhibited a low expression of MMP-9 protein that was markedly upregulated in response to $10 \mathrm{ng} / \mathrm{ml}$ LPS stimulation for $24 \mathrm{~h}$ (Fig. 2A). Anti-TLR4 neutralizing antibody pre-treatment reducedLPS-mediated MMP-9 protein expression (Fig. 2B). However, the addition of control IgG did not affect LPS-mediated MMP-9 protein expression. Furthermore, neutralizing anti-TLR4 did not affect MMP-9 protein expression in HASMCs (Fig. 2B).

Taken together, these results demonstrate that LPS induces MMP-9 expression and production in HASMCs in a TLR4-dependent manner.

TLR4 mediates LPS-induced activation of NF- $\kappa B$ in HASMCs. Nuclear extracts of HASMCs treated with LPS demonstrated a significant increase in $\mathrm{NF}-\kappa \mathrm{B}$ activation. The anti-TLR4 neutralizing antibody pre-treatment blocked this effect. The addition of control IgG did not affect LPS-induced NF- $\kappa \mathrm{B}$ activation (Fig. 3A). Furthermore, neutralizing anti-TLR4 had no effect on NF- $\kappa \mathrm{B}$ activation in HASMCs (Fig. 3B). These results demonstrate that LPS induces $N F-\kappa B$ activation in a TLR4-dependent manner in HASMCs.

LPS-induced MMP-9 expression is dependent on NF- $\kappa B$ activation. LPS potently induced NF- $\kappa \mathrm{B}$ activation in HASMCs, and this effect was blocked by neutralizing anti-TLR4. We investigated whether the changes in NF- $\mathrm{KB}$ activation correlated with the expression of MMP-9. PDTC has been demonstrated to be a potent antioxidant and inhibitor of $\mathrm{NF}-\kappa \mathrm{B}$ in in vivo and in vitro studies (15). In our study, $\mathrm{NF}-\kappa \mathrm{B}$ activation was targeted by PDTC (100 $\mu \mathrm{M}$ in PBS for $1 \mathrm{~h}$ ) (data not shown). To determine the role of NF- $\kappa \mathrm{B}$ in LPS-mediated MMP-9 expression, HASMCs were treated with PDTC (100 $\mu \mathrm{M}$ in PBS for 


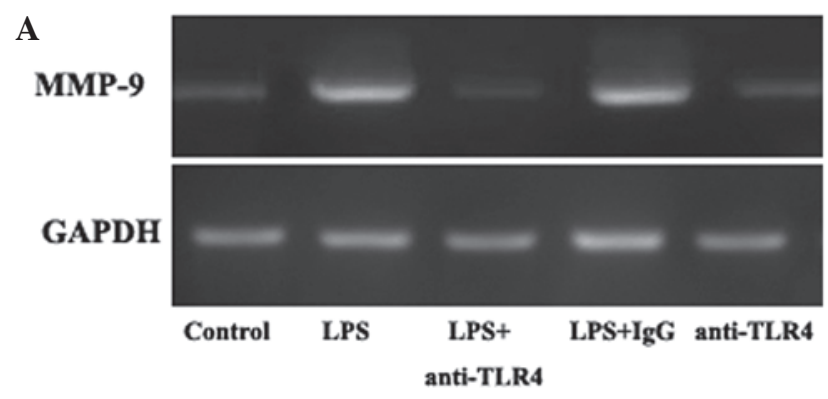

B

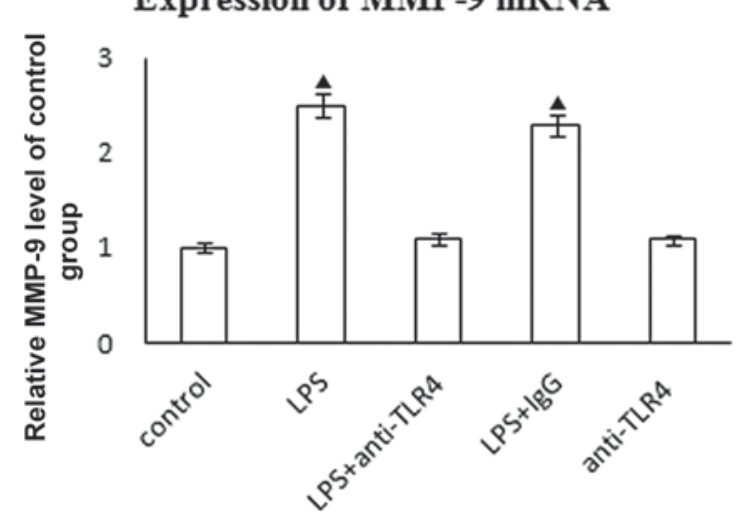

Figure 1. Gene expression of MMP-9 and GAPDH mRNA extracted from HASMCs by RT-PCR. (A) Semiquantitative RT-PCR for MMP-9 (389 bp) in HASMC was performed. GAPDH expression was used as control (175 bp). (B) Graph indicates relative MMP-9 mRNA expression by RT-PCR. ${ }^{\wedge}$ Compared with the control group $(\mathrm{P}<0.05 ; \mathrm{n}=7)$. Independent samples for each bar. MMP, matrix metalloproteinase; HASMC, human aortic smooth muscle cells; LPS, lipopolysaccharide; TLR, toll-like receptor.

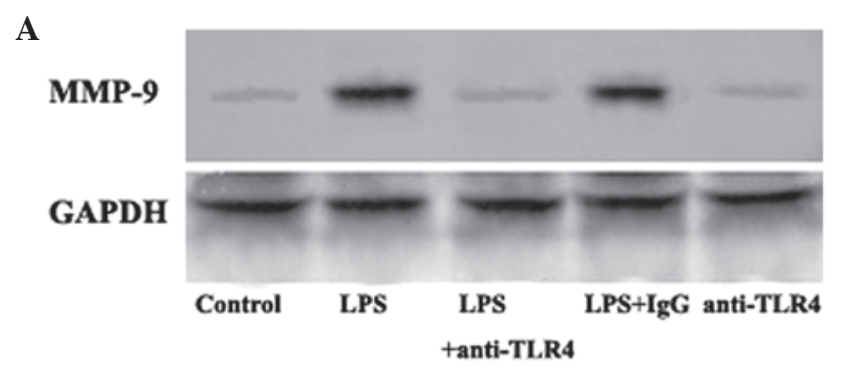

B

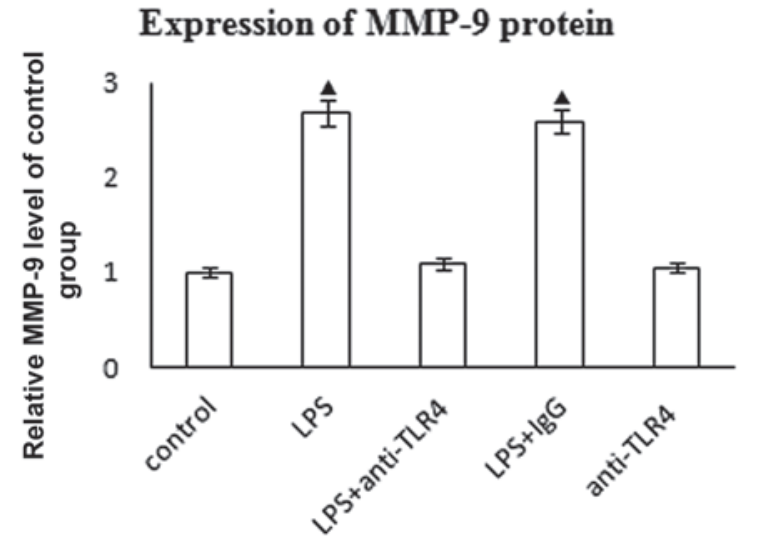

Figure 2. Protein products of MMP-9 and GAPDH extracted from HASMCs by western blot analysis. (A) Western blot for MMP-9 in HASMC was performed. GAPDH expression was used as control. (B) Graph indicates relative MMP-9 expression. ${ }^{\wedge}$ Compared with the control group $(\mathrm{P}<0.05 ; \mathrm{n}=7)$. Independent samples for each bar. MMP, matrix metalloproteinase; HASMC, human aortic smooth muscle cells; LPS, lipopolysaccharide; TLR, toll-like receptor.

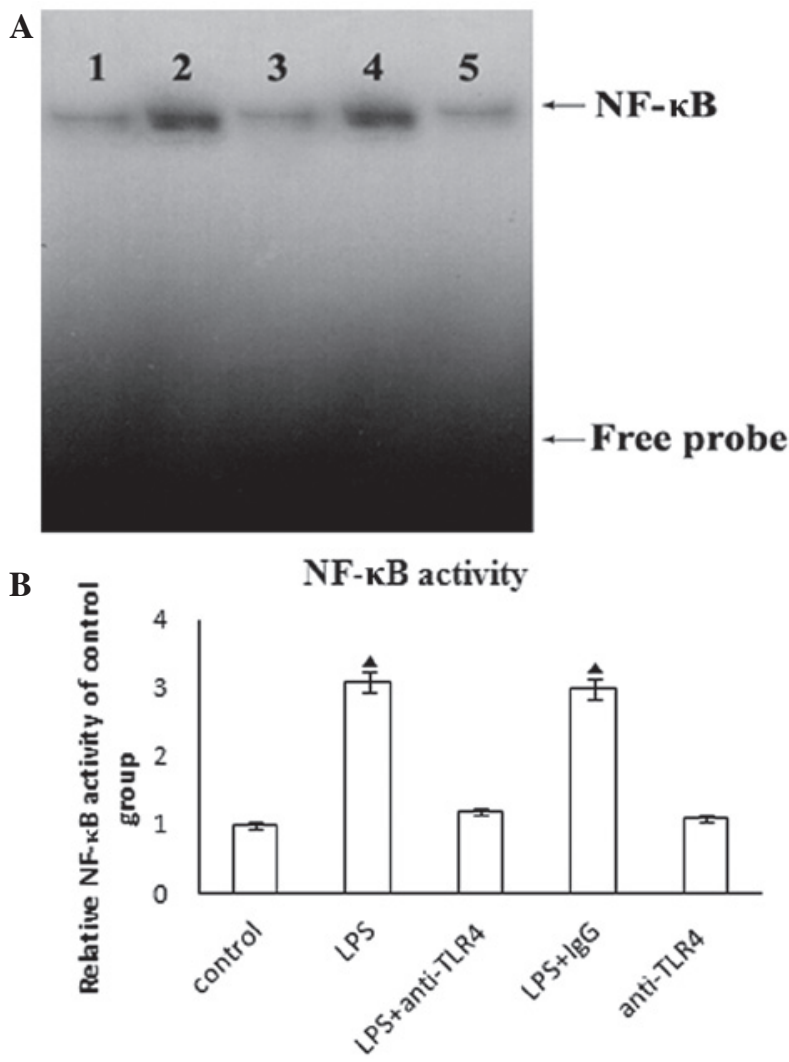

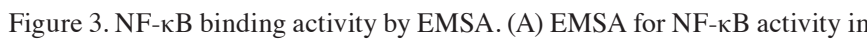
HASMC was performed. (B) Graph indicates relative NF- $\mathrm{kB}$ activity. Lane 1, control group; lane 2, LPS group; lane 3, LPS+anti-TLR4 group; lane 4, LPS+IgG group; lane 5, anti-TLR4 group. ${ }^{\circ}$ Compared with the control group $(\mathrm{P}<0.05 ; \mathrm{n}=7)$. Independent samples for each bar. NF- $\mathrm{B}$, nuclear factor- $\mathrm{\kappa}$; EMSA, electrophoretic mobility shift assay; LPS, lipopolysaccharide; TLR, toll-like receptor.

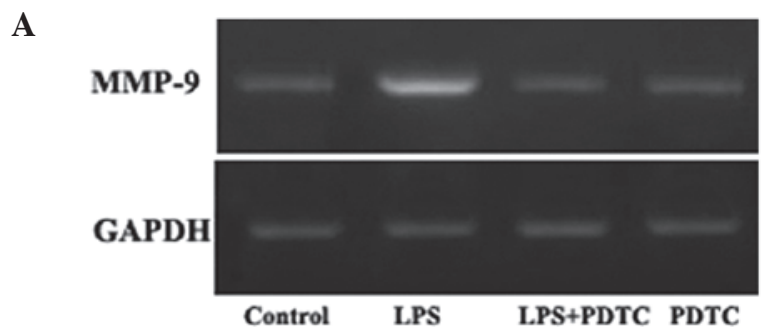

B

\section{Expression of MMP-9 mRNA}

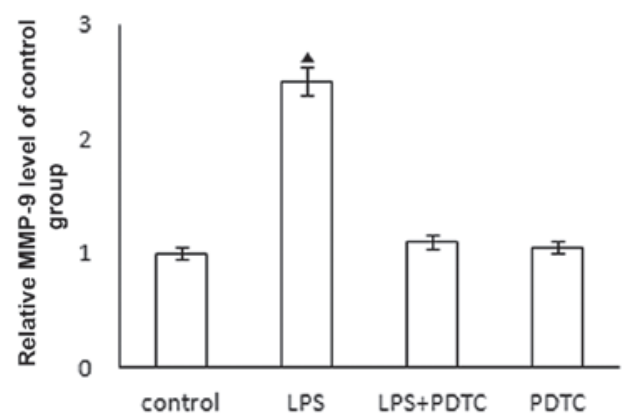

Figure 4. Gene expression of MMP-9 and GAPDH mRNA extracted from HASMCs by RT-PCR. (A) Semiquantitative RT-PCR for MMP-9 (389 bp) in HASMC was performed. GAPDH expression was used as control (175 bp). (B) Graph indicates relative MMP-9 mRNA expression by RT-PCR. ${ }^{\circ}$ Compared with the control group $(\mathrm{P}<0.05 ; \mathrm{n}=7)$. Independent samples for each bar. MMP, matrix metalloproteinase; HASMC, human aortic smooth muscle cells; LPS, lipopolysaccharide; PDTC, pyrrolidine dithiocarbamate. 
$1 \mathrm{~h})$ prior to the addition of LPS. Treatment with PDTC attenuated LPS-induced MMP-9 mRNA expression (Fig. 4A and B). Our results indicate that LPS induces MMP-9 upregulation in an $\mathrm{NF}-\kappa \mathrm{B}$-dependent manner.

\section{Discussion}

Endotoxin is important in the development and progression of atherosclerosis via the induction of TLR4-dependent proinflammatory cytokines, chemokines and adhesion molecule expression (16). MMP-9 expression is markedly enhanced in vascular stenosis following experimental balloon dilation and arterial restenosis following angioplasty (11). LPS has been demonstrated to stimulate MMP-9 expression in smooth muscle cells (14). However, how LPS regulates MMP-9 expression in HASMCs remains to be determined. In the present study, we demonstrated that LPS upregulates MMP-9 expression in HASMCs through TLR4/NF- $\kappa \mathrm{B}$ signaling.

MMP-9 is classified into the gelatinase sub-group of MMPs. Previous studies have demonstrated that the expression of MMP-9 is upregulated in the liver, spleen and kidney following bacterial LPS administration $(12,13)$. In the present study, we demonstrated that LPS upregulates MMP-9 expression in HASMCs. These results are in accordance with results of other studies (14). HASMCs expressed MMP-9 at low levels under basal conditions. LPS upregulated MMP-9 expression, and anti-TLR4 neutralizing antibody pre-treatment abolished LPS-mediated MMP-9 mRNA and protein expression. These results demonstrate that LPS induces MMP-9 expression and production in a TLR4-dependent manner in HASMCs. Findings of another study suggested that LPS induces the expression of genes encoding the elastin-degrading enzyme via TLR4 in human cervical smooth muscle cells (17). These proteinases allow SMCs to migrate to the site of inflammation or injury in response to chemokines (8). A clinical observation suggested that MMP-9 promoter is positively correlated with more rapid intima-media thickening (IMT) and constrictive remodeling (CR) progression (18). These studies lead to a pathogenic role for MMP-9 in vascular occlusive diseases.

$\mathrm{NF}-\kappa \mathrm{B}$ was first identified in the B-lymphocyte nucleus as a transcription factor that binds to an enhancer of the immunoglobulin $\kappa$ light chain gene. NF- $\kappa \mathrm{B}$ is able to mediate gene transcription by binding to specific sequences in the promoter regions of its target genes. LPS has been shown to induce activation of $\mathrm{NF}-\kappa \mathrm{B}$ in vivo (19). Our results also suggest that LPS induces NF- $\kappa \mathrm{B}$ activation in a TLR4-dependent manner in HASMCs. In our study, the nuclear extracts of HASMCs treated with LPS revealed significant increases in NF- $\kappa \mathrm{B}$ activation, and anti-TLR4 neutralizing antibody pre-treatment blocked this effect. Addition of the control IgG did not affect LPS-induced $\mathrm{NF}-\kappa \mathrm{B}$ activation. To determine the role of $\mathrm{NF}-\kappa \mathrm{B}$ in LPS-mediated MMP-9 expression, HASMCs were treated with PDTC prior to the addition of LPS. The results demonstrated that LPS stimulated MMP-9 expression in HASMCs, and that inhibition of NF- $\kappa \mathrm{B}$ blocks LPS-mediated MMP-9 upregulation, indicating that MMP-9 is an $\mathrm{NF}-\kappa \mathrm{B}$-responsive gene. Bea et al found that inhibition of the activation of proinflammatory transcription factors might reduce the synthesis of MMP-9 in vivo (20). These results suggest that LPS modulates MMP-9 expression through
$\mathrm{NF}-\kappa \mathrm{B}$ activation. However, other studies have suggested that there are other pathways involved in LPS-induced MMP-9 expression $(21,22)$. One of the explanations for this may be differences in species.

In conclusion, findings of the present study have shown that LPS upregulates MMP-9 expression in HASMCs through TLR4/NF- $\kappa \mathrm{B}$ signaling.

\section{Acknowledgements}

This study was supported by the Shanghai Rising-Star Program (08QA1404100) and the National Natural Science Foundation of China (30971265).

\section{References}

1. Nagase H: Activation mechanisms of matrix metalloproteinases. Biol Chem 378: 151-160, 1997.

2. Creemers EE, Cleutjens JP, Smits JF and Daemen MJ: Matrix metalloproteinase inhibition after myocardial infarction: a new approach to prevent heart failure? Circ Res 89: 201-210, 2001.

3. Lancelot E, Amirbekian V, Brigger I, Raynaud JS, Ballet S, David C, Rousseaux O, Le Greneur S, Port M, Lijnen HR, Bruneval P, Michel JB, Ouimet T, Roques B, Amirbekian S, Hyafil F, Vucic E, Aguinaldo JG, Corot C and Fayad ZA: Evaluation of matrix metalloproteinases in atherosclerosis using a novel noninvasive imaging approach. Arterioscler Thromb Vasc Biol 28: 425-432, 2008.

4. Furman C, Luo Z, Walsh K, Duverger N, Copin C, Fruchart JC and Rouis M: Systemic tissue inhibitor of metalloproteinase-1 gene delivery reduces neointimal hyperplasia in balloon-injured rat carotid artery. FEBS Lett 531: 122-126, 2002.

5. Fedak PW, Moravec CS, McCarthy PM, Altamentova SM, Wong AP, Skrtic M, Verma S, Weisel RD and Li RK: Altered expression of disintegrin metalloproteinases and their inhibitor in human dilated cardiomyopathy. Circulation 113: 238-245, 2006.

6. Tziakas DN, Chalikias GK, Papaioakeim M, Hatzinikolaou EI Stakos DA, Tentes IK, Papanas N, Kortsaris A, Maltezos E and Hatseras DI: Comparison of levels of matrix metalloproteinase-2 and -3 in patients with ischemic cardiomyopathy versus nonischemic cardiomyopathy. Am J Cardiol 96: 1449-1451, 2005.

7. Sun Y, Zhang JQ, Zhang J and Lamparter S: Cardiac remodeling by fibrous tissue after infarction in rats. J Lab Clin Med 135: 316-323, 2000.

8. Ogawa M, Suzuki J, Hishikari K, Takayama K, Tanaka H and Isobe M: Clarithromycin attenuates acute and chronic rejection via matrix metalloproteinase suppression in murine cardiac transplantation. J Am Coll Cardiol 51: 1977-1985, 2008.

9. Lee SO, Chang YC, Whang K, Kim CH and Lee IS: Role of NAD(P)H:quinone oxidoreductase 1 on tumor necrosis factor-alpha-induced migration of human vascular smooth muscle cells. Cardiovasc Res 76: 331-339, 2007.

10. Otero-Viñas M, Llorente-Cortés V, Peña E, Padró T and Badimon L: Aggregated low density lipoproteins decrease metalloproteinase-9 expression and activity in human coronary smooth muscle cells. Atherosclerosis 194: 326-333, 2007.

11. Cho A and Reidy MA: Matrix metalloproteinase-9 is necessary for the regulation of smooth muscle cell replication and migration after arterial injury. Circ Res 91: 845-851, 2002.

12. Abe K, Ikeda T, Wake K, Sato T, Sato T and Inoue H: Glycyrrhizin prevents lipopolysaccharide/D-galactosamine-induced liver injury through down-regulation of matrix metalloproteinase-9 in mice. J Pharm Pharmacol 60: 91-97, 2008.

13. Pagenstecher A, Stalder AK and Kincaid CL: Regulation of matrix metalloproteinases and their inhibitor genes in lipopolysaccharide-induced endotoxemia in mice. Am J Pathol 157: 197-210, 2000.

14. Lin SJ, Lee IT, Chen YH, Lin FY, Sheu LM, Ku HH, Shiao MS Chen JW and Chen YL: Salvianolic acid B attenuates MMP-2 and MMP-9 expression in vivo in apolipoprotein-E-deficient mouse aorta and in vitro in LPS-treated human aortic smooth muscle cells. J Cell Biochem 100: 372-384, 2007. 
15. Beswick RA, Zhang H, Marable D, Catravas JD, Hill WD and Webb RC: Long-term antioxidant administration attenuates mineralocorticoid hypertension and renal inflammatory response. Hypertension 37: 781-786, 2001.

16. Hongli Li and Baogui Sun: Toll-like receptor 4 in atherosclerosis. J Cell Mol Med 11: 88-95, 2007.

17. Watari M, Watari H, Nachamkin I and Strauss JF: Lipopolysaccharide induces expression of genes encoding pro-inflammatory cytokines and the elastin-degrading enzyme, cathepsin S, in human cervical smooth-muscle cells. J Soc Gynecol Invest 7: 190-198, 2000.

18. Fiotti N, Altamura N, Fisicaro M, Carraro N, Adovasio R, Sarra VM,UxaL, Guarnieri G,BaxterBT andGiansante C:MMP-9 microsatellite polymorphism: association with the progression of intima-media thickening and constrictive remodeling of carotid atherosclerotic plaques. Atherosclerosis 182: 287-292, 2005.

19. Tsai CS, Lin FY, Chen YH, Yang TL, Wang HJ, Huang GS, Lin CY, Tsai YT, Lin SJ and Li CY: Cilostazol attenuates MCP-1 and MMP-9 expression in vivo in LPS-administrated balloon-injured rabbit aorta and in vitro in LPS-treated monocytic THP-1 cells. J Cell Biochem 103: 54-66, 2008.
20. Bea F, Kreuzer J, Preusch M, Schaab S, Isermann B Rosenfeld ME, Katus $\mathrm{H}$ and Blessing E: Melagatran reduces advanced atherosclerotic lesion size and may promote plaque stability in apolipoprotein E-deficient mice. Arterioscler Thromb Vasc Biol 26: 2787-2792, 2006.

21. Lee SY, Kim HJ, Lee WJ, Joo SH, Jeon SJ, Kim JW, Kim HS, Han SH, Lee J, Park SH, Cheong JH, Kim WK, Ko KH and Shin CY: Differential regulation of matrix metalloproteinase-9 and tissue plasminogen activator activity by the cyclic-AMP system in lipopolysaccharide-stimulated rat primary astrocytes. Neurochem Res 33: 2324-2334, 2008.

22. Marcet-Palacios M, Ulanova M, Duta F, Puttagunta L, Munoz S, Gibbings D, Radomski M, Cameron L, Mayers I and Befus AD: The transcription factor Wilms tumor 1 regulates matrix metalloproteinase- 9 through a nitric oxide-mediated pathway. J Immunol 179: 256-265, 2007. 